\title{
CONTEXT-AWARE SERVICES IN COOPERATIVE VALUE CHAINS: A KEY PLAYER-CENTRED APPROACH
}

\author{
CHRISTINE BAUER $†$ CHRISTINE STRAUSs $\ddagger$ CHRISTIAN STUMMER§ AND ALEXANDER TRIEB
}

\begin{abstract}
The progress in context-aware systems is predominantly technology-driven, leading to innovations in technologysavvy industries while having almost no impact on other industries, such as the insurance sector. In this paper we introduce a novel, key player-oriented framework that explicitly takes into account the (business) value for each player being relevant when implementing a particular context-aware service on the market. We illustrate the framework's applicability by means of a case study of a context-aware system that allows for monitoring high-value items for insurance purposes.
\end{abstract}

Key words: context-aware service, key player, value-orientation, business value, business approach, insurance sector, highvalue items monitoring

AMS subject classifications. 93A02, 94A02

1. Introduction. Advanced hardware miniaturisation, the continuous increase of capabilities for communication, processing, and storage, as well as the proliferation of electronic devices are key drivers towards context-aware computing applications. Although context-aware technologies are becoming more reliable and cost efficient and, thus, businesses are exploring ways in which they can leverage them for novel services in order to improve their market position [4], there is still no consensus on what they should be used for [21] and how to realise the vision of the internet of things [17].

Innovation in the field of context-aware systems is mostly technology-oriented, in fact even technologydriven [21]. Following this approach, the innovation potential has started to (slowly) emerge within traditional manufacturing as well as in distribution and retail industries [9], but so far had no or just negligible impact on other industries. As we will show in our case study from the insurance sector, the reason for the hampered adoption of context-aware computing neither lies in the non-applicability of context-aware computing nor in the lack of creativity to come up with new ideas. Rather, many industries are driven by business value considerations instead of being predominantly pushed by technology. As a result, benefits expected from an investment in a new business idea have to clearly exceed the anticipated risks. To this end, Fleisch and Tellkamp [8] proposed a framework aiming at identifying value-creating applications in the ubiquitous computing domain, focusing on the "challenges identifying value-creating applications both ex ante and ex post". This framework later on was extended by Strauss et al. [27], who introduced a decision support guide for the evaluation of the value of an envisaged service that may be used by businesses to decide based on quantitative criteria whether or not to invest in a project and offer a novel service. They also provided a case study on damage prevention, where they analysed the function of several market players from different fields in offering a context-aware computing solution. They show that each market player fulfils a crucial role in realising the particular service.

Such two-sided or multi-sided markets, in which two or more distinct user groups benefit from each other by interacting on the market [18], can be found in several industries (e.g., health sector, telecommunications, gaming industry, etc.). The market for credit card services, for instance, comprises cardholders, financial institutions, merchants with a wide-spread network, and developers of credit card readers; all these market players make up a market by cooperating and establishing mutual trust. Offering context-aware services also typically relies on several market players, i.e., hardware suppliers who provide the technological infrastructure, service providers who use this infrastructure to provide their services, and (end-)users consuming the service [2]. Since a service cannot be realised in the absence of any of these stakeholders, benefits and risks of each key player have to be

\footnotetext{
${ }^{\dagger}$ Vienna University of Economics and Business, Department of Information Systems and Operations, Welthandelsplatz 1, 1020 Vienna, Austria (chris.bauer@wu.ac.at).

$\ddagger$ University of Vienna, Faculty of Business, Economics and Statistics, Oskar-Morgenstern-Platz 1, 1090 Vienna, Austria (christine.strauss@univie.ac.at).

$\S$ Bielefeld University, Department of Business Administration and Economics, Universitätsstraße 25, 33615 Bielefeld, Germany (christian.stummer@uni-bielefeld.de).

I travel audience GmbH, Mozartstraße 4b, 53115 Bonn, Germany (a.trieb@travelaudience.com).
} 
balanced such that the envisaged service can be realised.

Two alternative scenarios for market development have been observed in practice. The first one is driven by a cooperative network [13] that is formed in five phases (i.e., initiation, forming, storming, norming, performing [28]) during which potential business partners get to know each other, build mutual trust, and set joint goals. Then they jointly elaborate a business idea, for which each potential network partner individually evaluates its own benefits, costs, and risks. In the second scenario, one entity (i.e., an organisation or an entrepreneur) propels the business idea and strives to 'sell' it to other businesses that are required to operationalise the idea. In this case, we assume that potential partners may be convinced more easily if expected benefits are evident. This constitutes the starting point for our research: Given business-value as major driver as well as multi-sided markets, the paper at hand proposes a novel procedural framework that uses a 'key player-centred approach' to identify valuable context-aware services.

The remainder of this work proceeds as follows: Firstly, we discuss existing approaches and related work (Sect. 2). Next, we introduce our novel framework that puts the key players' benefits into the centre (Sect. 3). Then, we show the applicability of the framework by means of an exemplary case study, i.e., the context-aware service for monitoring high-value items in the insurance industry. This case study demonstrates the framework's value in leveraging context-aware computing technologies to gain benefits for both insurance companies and their customers (Sect. 4). The final section summarises the research contributions of our work (Sect. 5).

2. Related Work. In this section, we present selected research on evaluation and valuation; this section is the foundation of and justification for the framework, which we present in Sect. 3 .

In an attempt to add a perspective that differs from the (usual) orientation on technological issues, Oulasvirta [21] postulated that any technology should be leveraged for the service on humanity and, therefore, research needs to be directed towards the technology's relevance to people, the understanding of people and their activities, and the empowerment of people themselves to address their needs for design goals. This approach borrows from user-centered (product concept) design [16, 20], which is widely adopted in the field of human-computer interaction (HCI). However, putting user needs into the loop is not sufficient to make a business idea economically feasible.

Social computing [25] deals with embedding technology in a social context and emphasises that social change, that has been caused by technology, has to be considered as well. Analogously, the value-sensitive design approach by Friedman [10] places emphasis on the role of human values and morals in deciding what features or characteristics of technology are relevant and are particularly worth of being further pursued in system design (e.g., user autonomy). This approach, however, does not take economic feasibility into account. Furseth, Cuthbertson, and Reynolds [11], in contrast, argue that service innovation is "driven by the value created for the customer, where value may be defined in both economic and social terms". While this point of view imbeds the customer's value, it still remains one-sided because this value does not automatically translate into willingness to pay for a service (which may be particularly true in a "for free-economy" setting) or leads to (other) revenues that may at least even out the costs. Therefore, the critical question remains how an entity (e.g., a company) should be motivated to offer a service that does not promise a positive, direct or indirect, value for the provider.

The framework by Fleisch and Tellkamp [8] addresses this issue by analysing the value for each participating entity (with respect to both tangible and intangible benefits). As shown in Fig. 2.1, potential sources of value can only yield benefits for the involved entities when several challenges, referring to the network, constraints, implementation issues, and valuation, have been overcome. Analysing network effects is necessary in order to get a clear(er) picture of the potential sources of value. Constraint challenges may inhibit that the entire project can be realised. Implementation challenges refer to limited resources and knowledge in the implementation phase or during actual use of the service. While network, constraint, and implementation challenges diminish the value of a project or hinder its realisation, valuation challenges are problems of determining the tangible benefits from a service either ex ante or ex post.

For their decision support framework, Strauss et al. [27] adopt the above concept, and enrich it further with a scenario technique to allow a decision whether or not to invest in an innovation based on feasibility and efficiency criteria. Although cost forecasts are no explicit part of their framework, they build the basis for a (quantitative) assessment based on different prototypical scenarios. Their framework suggests to have a 


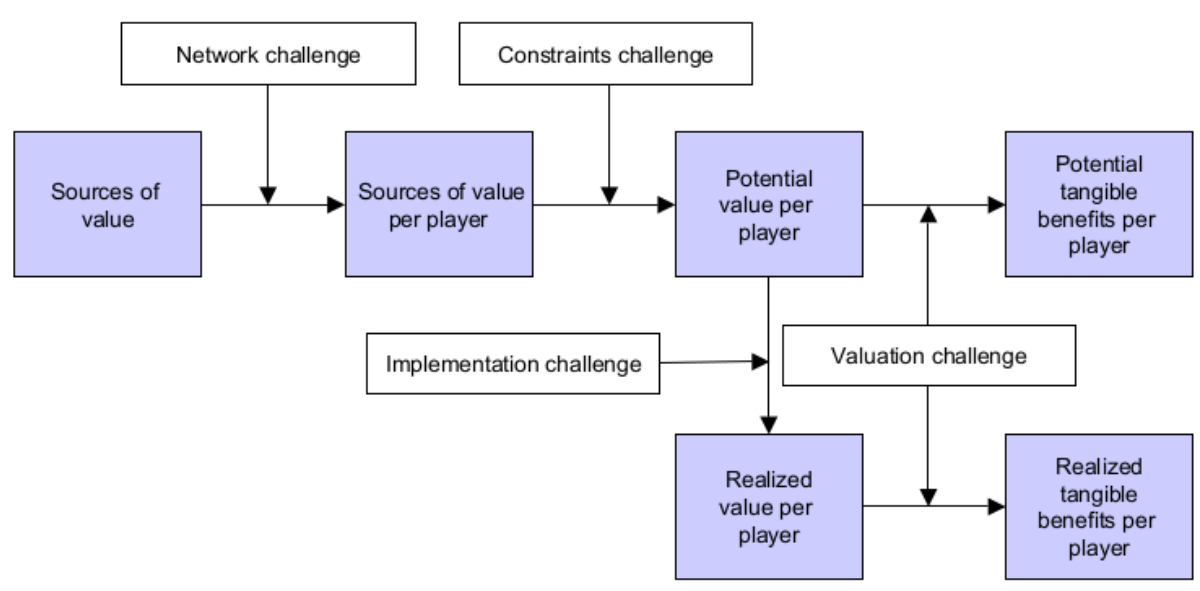

FIG. 2.1. A framework for identifying value-creating applications in ubiquitous computing [8]

much closer look at the costs and tangible benefits (by including pessimistic and optimistic estimates to provide a spectrum in costs and relative values of tangible benefits) and to develop both aggressive and conservative scenarios to be able to identify differences in customer-related drivers (e.g., number of sensors per site). Thus, a more reliable basis for the decision on whether or not to invest in an innovative service can be established.

Pang et al. [22], finally, claim a 'business-technology joint design' intended to cross the gap between industrial business practices and technology development. Both, technical and business challenges, have to be resolved simultaneously to bring successful context-aware solutions into the market. They emphasise that value creation on the business side is essential, and information and technical requirements have to build on and towards this business value. Further, they argue that a value-centric approach is superior to a technology-centric one as users will pay for values, not for technologies. In following such a value-centric approach, the value creation should be related to the entire set of stakeholders of the envisaged service.

3. The Key Player-centred Framework. Developing a framework is an inherently iterative search and design process that follows continuous cycles of generating and evaluating design alternatives. Accordingly, we gradually improved the framework and used group reflection phases after each generation/evaluation cycle to foster them towards the final coherent framework. For evaluation purposes we chose an ex post approach (cf. the strategic evaluation framework of Pries-Heje et al. [23]). The work of Venable et al. [29] proved as a useful guide in choosing an appropriate method. Out of the seven methods that support an ex post approach, we finally opted for the case study approach, because it illustrates not only the benefits very clearly, but also delivers a proof of concept. The case study will be presented in Sect. 4 .

For an overview of the procedural framework see Fig. 3.1. It starts with a business idea for a context-aware service in a given domain that recombines resources in a way that allows for pursuing a business opportunity [26]. Typically, this includes selling a product or a service, although alternative approaches exist as well (e.g., business models that offer free services to users and are financed through advertising).

The next step is the identification of relevant key players, who have to commit to a project, such that the idea can be realised. While some projects may be realised by only one key player, most business ideas including context-awareness require the cooperation of several players (e.g., $[3,5])$.

In a commercial setting, each of the key players has to get the opportunity to gain some (individual) value from the envisaged service (otherwise, they would not contribute). The third step in the process is therefore dedicated to identifying and determining the benefits for each key player. These benefits may be tangible (e.g., profit, reduced employee turnover, reduced costs, etc.) or intangible (e.g., improved employee morale, heightened customer loyalty, better vendor relationships, image improvement, etc.).

After having successfully determined benefits for each of the key players, scenarios for the envisaged service need to be developed. For three reasons the development of scenarios has to be performed independently of any 


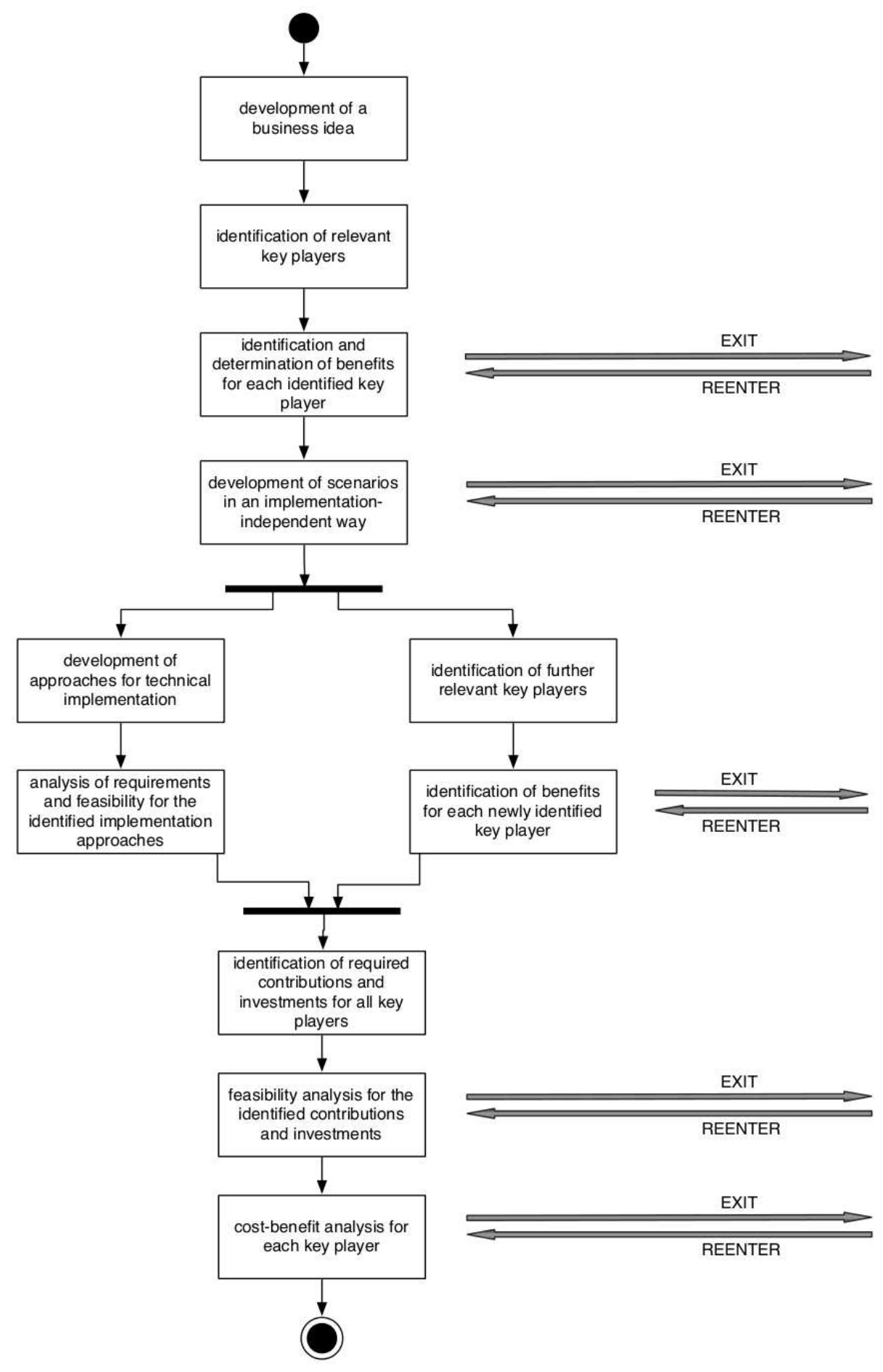

FIG. 3.1. The key player-centred approach 
(possible) technical implementation: First, the scenarios should be defined by managers, while the technical implementation possibilities will be identified by people with technical background (e.g., computer scientists, engineers), who come into play at a later stage. Second, services envisioned may not be technically feasible in a certain point in time, but later on they might. As a result, it will be easier to come back to the scenarios later when it is described in an implementation-independent way, whereas any implementation-driven approach would require to start over in elaborating the scenarios. Third, for context-aware services, context is the pivotal element. Similar to the definition of functionality of the envisaged service, context should be defined as required from the business perspective because, from a technological perspective, sourcing context can be performed in various ways. For instance, Dobson [6] presents a non-exhaustive taxonomy of 18 different implementation approaches to gather location context information, in many cases derived from other sources than from explicit location-sensing hardware at all.

After the development of scenarios, technical implementations for the scenarios have to be identified. These implementation alternatives should then be analysed for requirements and feasibility. This will include considering the pros and cons of the various implementation approaches. As technical experts are usually aware of what is currently possible from a technical perspective, we expect that the two steps of identifying implementation alternatives and evaluating them might coincide in most cases.

While engaging with technical issues, a second, parallel thread in the process takes again a business perspective. Based on the developed scenarios, it should be verified if the key players involved so far will be able to cover all aspects described in the scenarios, or if additional players need to be considered to realise the new service project. In the latter case, benefits need to be identified also for the newly identified key players.

After having successfully addressed both, the technical as well as the managerial thread, the process continues with the identification of required contributions and investments of each key player. Such contributions and investments may be of various nature including process adaptation, distribution, marketing efforts, financial contribution, provision of space, legal advice, technology, or networks and so forth. Having identified the required contributions, another analysis concerns the feasibility and prospective willingness of key players to contribute as required. Finally, a cost-benefit analysis for the envisaged service has to be performed separately for each key player involved.

As Fig. 3.1 indicates, there are several exit points throughout the process that allow to abandon the project, either completely (e.g., if only insufficient benefits can be identified) or with the intent to resume the project at a later point in time (e.g., if technologies have to be more advanced before a service can be realised in the required way). Therefore, each exit point is at the same time a possible "point of return" to reenter the project, when, for instance, technology is more advanced, additional benefits have been generated for one of the key players, etc.

4. A Case Study in the Insurance Sector for Monitoring High-Value Items. In the following, we describe a case study from the insurance industry, in which a context-aware infrastructure is leveraged to gain benefits for insurance companies, their customers, and other key players involved. The presented case is based upon the premise of providing anxiety-relieving monitoring and risk services by being always connected, always aware, and demonstrating pro-activity with the customer.

4.1. Business Idea: Wireless Monitoring of High-Value Items. The insurance industry is confronted with an increasing number of theft incidents. A context-aware infrastructure could offer a solution to minimise the issues of theft or damages particularly for high-valued insured items (e.g., paintings, sculptures, furniture, jewellery, tapestries, antiques). Many of these valuable items are typically not placed in a high-security location and may for this reason be targeted in a burglary. Besides the monetary value, the emotional value of such items to the owner should not be underestimated. Therefore, customer loyalty may be substantially increased, once a solution can be provided that improves the likelihood of recovering stolen items.

The principle business idea is to provide a context-aware service that allows for monitoring the current state of high-value items, including tracking their location and environment conditions. In case of a critical event, the item's owner (i.e., the insured customer) as well as the insurance company are instantly notified, and stolen items are automatically registered at dedicated institutions for art theft. 
4.2. Identification of Relevant Key Players and their Benefits. The primary stakeholders of the envisioned context-aware service include the insurance company and the insurance customer (i.e., the owners). Within the insurance company, the users of a system that processes data for this service will include the insurance agent, insurance appraiser, and customer service representatives. Granting professional art historians and dealers access to the system would further streamline the evaluation process of high-valued items. The tangible and intangible benefits identified from the perspective of the insurance company are summarised in Tab. 4.1.

TABLE 4.1

Benefits for insurance companies

\begin{tabular}{lr}
\hline Tangible Benefits & Intangible Benefits \\
\hline Reduction in Claims Expenses & Increased Customer Loyalty \\
Reduction in Administrative Overhead & Increased Brand Awareness \\
Reduction in Customer Visits & Improved Customer Retention \\
Increase in Premium Revenues & Improved Efficiency of Resources \\
& Reduction in Theft Risk \\
\hline
\end{tabular}

Reduction in claims expenses would offer the most obvious tangible benefit for the insurance company due to the higher probability of recovering stolen items and the minimisation of damages requiring substantial repair and restoration expenses. Moreover, even the administration overhead for claims could be reduced by automatically initiating the pre-filling of the claim with the required information, such as items missing, time of day, location, insurance policy holder, or total projected claims value. Cost savings in administration may be relatively low compared to the other expenses mentioned before; however, this feature would demonstrate pro-activity to the customer, and thus may contribute to positioning the insurance company as a trustworthy helper and problem solver.

Moreover, being the first insurance company to offer such a service, the corresponding first mover advantage may yield an increase in overall premiums as a result of a potential rise in market share attested to growing interest and demand of the innovative solution. Also, customer visits from insurance appraisers and other professional art historians could be reduced when online communication capabilities are realised through the micro-portal, i.e., a network and platform on which art dealers, appraisers, customers and agents can interact. Furthermore, a potential network effect could arise through the instalment across the entire customer base, which may contribute to a general decline in theft risk, which, again, may translate into lower premium needs that may be passed on to the customers as an additional incentive.

The tangible and intangible benefits identified from the perspective of the insured customer are summarised in Tab. 4.2. Overall, the envisaged service may contribute to resolving the insurance companies' dilemma between the customers' expectation of strong commitment to safety and security of their high-valued items on the one hand, and an increasing price-sensitivity on the other hand.

TABLE 4.2

Benefits for insured customers

\begin{tabular}{lr}
\hline Tangible Benefits & Intangible Benefits \\
\hline Reduction of Premiums & High Safety and Security \\
Reduction in Administrative Efforts & Increased Emotional Value \\
Reduced Damages & Increased Recovery Probability of Stolen Items \\
& Increased Improved Service Quality \\
\hline
\end{tabular}

4.3. Scenario and Functionality: Wireless Monitoring of High-Value Items. Based on the principle business idea (cf. Sect. 4.1), a set of scenarios were elaborated and described in detail. Based on these scenarios, various functions for a context-aware monitoring service provided by an insurance company were derived and listed in Tab. 4.3. This list includes inventory management functionality that allows for adding and deleting items and for updating item information. Further, information from all insured items at each location 
is aggregated and, thus, available for analysis purposes. Alert messages from a base station are constantly monitored; in case of an alert, customers are automatically notified via short messaging (SMS), e-mail, and/or through an insurance representative (e.g., broker, agent, or service representative), and the claims process is automatically triggered. Stolen items are identified in real-time, and potential claim damages are immediately assessed. Moreover, stolen items are automatically registered at two major web services for registering stolen art: Interpol's Recent Thefts Database [15] as well as at Art Loss Registry [1].

The probably most appealing functionality is the monitoring of items at any time via a web interface. This feature is particularly important to monitor items in transit for additional protection and to track stolen items to locate and recover them within a short timeframe. Environmental conditions may also be monitored which allows for fast notification of potential damages and quick response in order to minimise the extent of such damages. Optimal temperature and humidity conditions are essential, for instance, for paintings. Furthermore, historical data on environmental conditions are collected to reveal new risks or long-term effects.

TABLE 4.3

Functions of the context-aware monitoring service

\begin{tabular}{l}
\hline Functions \\
\hline Inventory management \\
Aggregation of information from all insured items \\
Monitoring of alert messages \\
Automatic notification of critical events to the customer \\
Real-time identification of stolen items \\
Real-time assessment of potential claim damages \\
Automatic registration of stolen items at Interpols Recent Thefts Database \\
Automatic registration of stolen items at the Art Loss Registry \\
Online tracking of items \\
Monitoring of items in transit \\
Historical data of environment conditions
\end{tabular}

Via a customer web portal (for functionalities cf. Tab 4.4), each customer has an up-to-date record on the entire inventory of his or her insured items, which contains a description, photographs, and information about the value of each item. An inventory management component enables to add and delete items and to update information on insured items. This component further manages the insurance policy and the premium payments. When new items are added, its documentation is automatically verified by notifying an insurance appraiser or professional during the operation. Further, a customer can access information of insured items' environmental conditions via the web portal at any time. Items in transit may be monitored to constantly be informed of their locations. In addition, the portal provides a direct communication channel to an insurance representative (i.e., agent, broker, customer service representative, etc.).

TABLE 4.4

Functions of the customer web portal

\begin{tabular}{l}
\hline Functions \\
\hline Presentation of the entire inventory of insured items \\
Online inventory management \\
Automated adding and documenting of the inventory \\
Automatic verification of the documentation of a new item \\
Presentation of environmental conditions \\
Monitoring of items in transit \\
Direct communication channel to an insurance representative \\
\hline
\end{tabular}

Overall, the envisioned context-aware service allows for identifying each individual insured item, providing sensing information of environmental conditions, automating alert messaging, responding pro-actively to critical events, and increasing recovery probability of stolen items. 
4.4. Technical Implementation and Feasibility Analysis. The envisaged context-aware system is composed of sub-systems for data gathering, data communication, data analysis and monitoring, as well as item tracking and recovery processes. The data gathering process is responsible for capturing environmental conditions as well as security events. The latter may be the movement of an item or the vibration of a painting that is being cut out of its frame. These events are captured by a central reader that filters the information and forwards the data to the backend context-aware insurance system via the cellular network. Figure 4.1 provides an overview of the technical architecture of the proposed context-aware service solution.

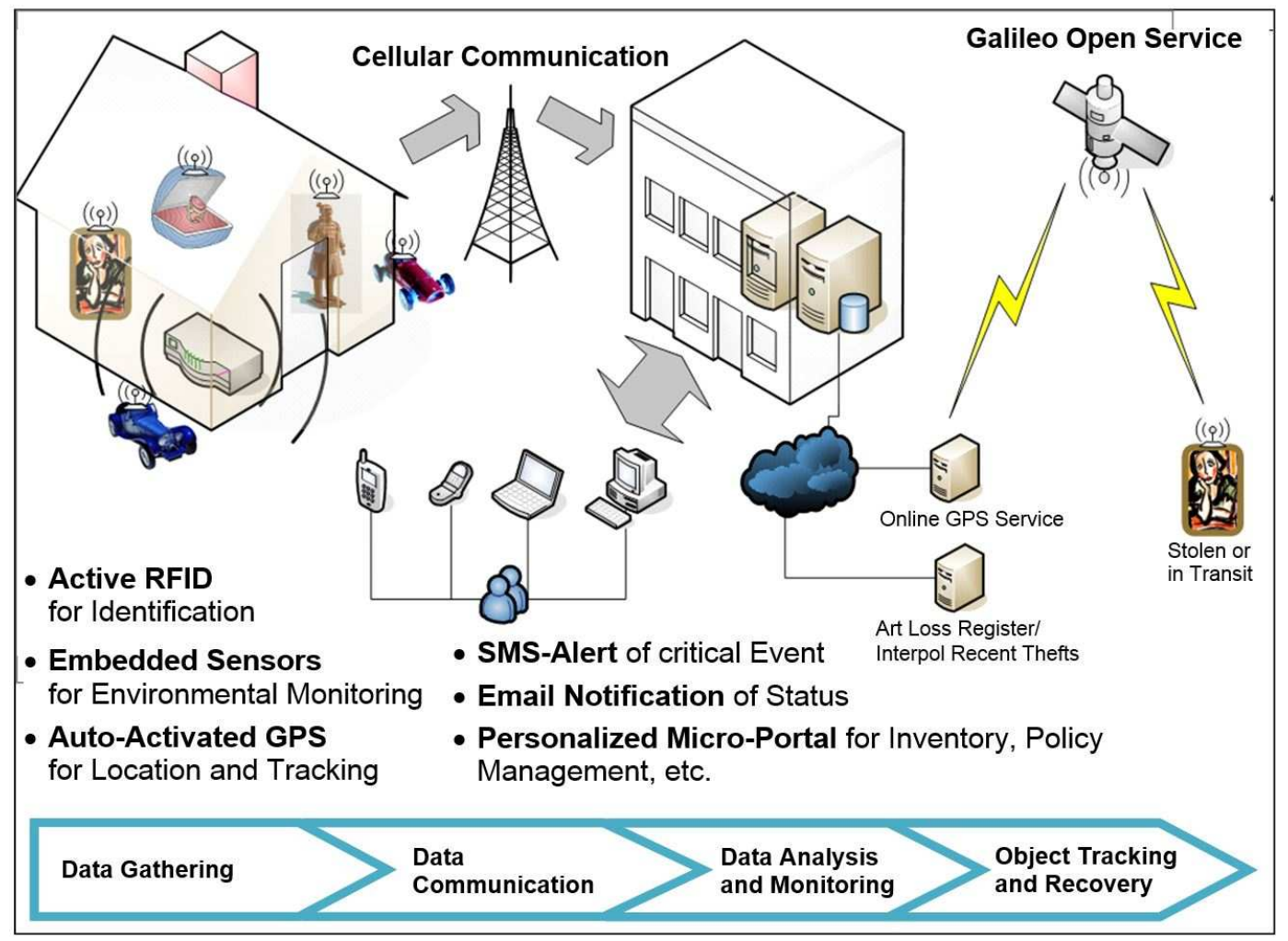

FIG. 4.1. Technical architecture for the high-value items tracking solution

The individual tags are comprised of Class 3 semi-passive Radio Frequency Identification (RFID) tags with integrated humidity, temperature, and vibration sensors including an embedded Global Positioning System (GPS) and General Packet Radio Service (GPRS) communication module. Figure 4.2 summarises the proposed component architecture of the tag. Class 3 semi-passive RFID tags were chosen over alternative tag types due to their lower monetary costs (compared to active RFID tags), read/write capabilities, integrated sensors, extended signal range, and built-in security. The tags exhibit additional benefits such as maximisation of the life span of the power source due to the so-called 'deep sleep' mode as well as the backward compatibility to standard passive tags [7]. The 'deep sleep' mode allows tags to use battery when signals are received from the reader. When in 'deep sleep' mode, the tag reverts to the standard inductive method found in standard passive tags. Through this capability, the tags could have an expected sensing lifespan of over five years with transmission intervals of every 20 seconds and an unlimited identification lifespan.

The tags also include GPS with an integrated GPRS communication module to enable real-time tracking during the event of a theft. Due to the high power requirements of GPS modules, they would remain in a nonoperational state until the RFID signal gets lost or vibrations are sensed; when this happens, it can be assumed that the high-valued item is being stolen. If so, the GPS module switches into location and tracking mode and GPRS communication is used to send the GPS coordinates to an online server which allows external companies, such as insurance companies, to retrieve the tracking information via a standard web service interface. The high 


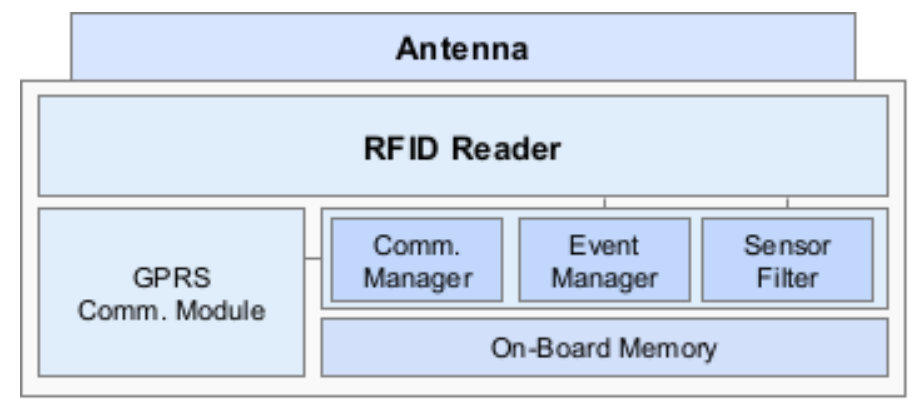

FIG. 4.2. Customised RFID tag

power consumption of the GPS and GPRS modules shortens the further lifespan of a tag to a few months. It is assumed, however, that the time required to locate and retrieve a stolen item will be accomplished within this time frame. Note, that we suggest to add temperature and humidity sensors in order to provide an additional advisory service: tracking humidity and temperature conditions for an insured item enables an alert at the base station once the measured values either exceed or fall below some predefined (acceptable) threshold values. This service could prevent or at least minimise additional damage.

The proposed solution requires the installation of a base station, which incorporates an RFID reader, software components, and a cellular communication module. Figure 4.3 provides an overview of the technical components of the base station. The RFID reader aggregates information collected from the tagged items. The software component manages the aggregation, filtering, and exchange of information. The event manager listens to the sensor filter component and and alerts the context-aware insurance system, if temperature or humidity either exceed or fall below some predefined threshold values or the vibration sensor has been triggered. Events can also be timed-based in order for historical data, which can be stored in the on-board memory, to be sent to the context-aware insurance system on a daily, weekly, or monthly basis. The connection is established through the GPRS cellular network; a standard Internet Protocol (IP) connection is used for the communication between the backend servers and the reader, which in essence is a traditional client-server connection.

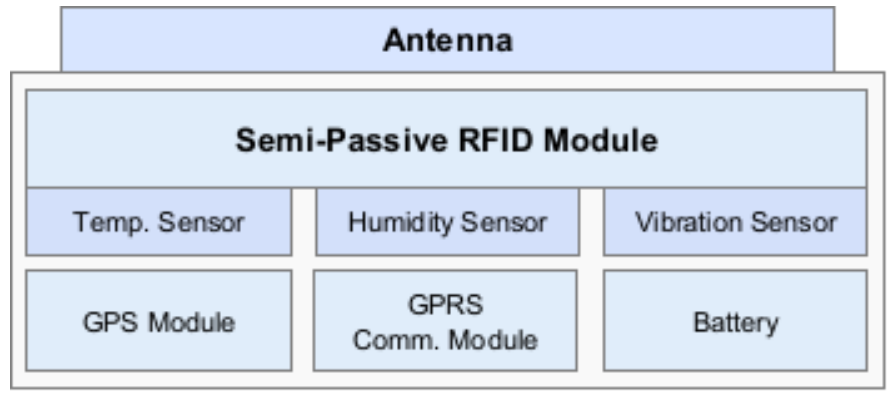

FIG. 4.3. Base station architecture

The data analysis and monitoring process is characterised by the exchange, storage, analysis, and presentation of data. Due to the IP based connection between the base station and the backend system, an existing middleware, workflow management, and database infrastructure for message passing, event triggering, and data storage could be used. Both the insurance company and the customer can access the information through various web-enabled devices such as mobile devices, tablets, and laptops.

Finally, a feasibility analysis has to be performed for this envisaged implementation in terms of technology as well as in terms of limited resources.

4.5. Identification of Additional Key Players and their Benefits. In the course of describing the envisioned context-aware service and its functionality in more detail, Interpol and the Art Loss Registry have been identified as additional key players. Currently they run the Recent Thefts Database [15] and the Art Loss 
Registry [1] as web services that allow for registering stolen art and provide an opportunity for art dealers to check whether an offered item has been reported stolen. If these two players would limit or close their services, the benefits of the envisioned context-aware service would decrease. The benefits for these two players have been summarised in Tab. 4.5.

TABLE 4.5

Benefits for Interpol and the Art Loss Registry

\begin{tabular}{lr}
\hline Tangible Benefits & Intangible Benefits \\
\hline Reduction in Administrative Overhead & Improved Efficiency of Resources \\
Increased Usage of their Databases & Increased Quality of Service \\
\hline
\end{tabular}

Also, an online tracking provider is essential for the context-aware service; an appropriate candidate needs to be found and integrated. Similar to Interpol and the Art Loss Registry, the online tracking provider would benefit from the service through an increased demand of its specific services, which also may have a positive impact on the image of this provider.

Another expansion could include police departments and/or a security company. This would allow for an automatic notification of stolen items as well as for the exchange of information regarding the description (including photographs) and the location, which may help to speed up the recovery of stolen items. Thus, the success rate in the recovery of stolen items may increase.

Given that insurance products and related services may be complementary to existing products and/or services, a partnership between an insurance company and system integrators or security providers could be worth to be considered. The context-aware service would then only be a specific functionality offered with an existing security system. Still, the monitoring information should be made available through the insurance company in order to establish and maintain a constant communication channel between insurer and customer. For the further analysis in this case study, however, we stick with the original idea that an insurance company offers the context-aware service.

4.6. Identification of Required Contributions and Investments. After having gathered the primary functions and designed the technological architecture for the context-aware service, this section elicits contributions and investments necessary for its realisation.

Insurance Company. The realisation of the technical architecture would require an initial investment for the customised development of the underlying monitoring system, the base station software (assuming that software based on these requirements does not exist), and the installation. For running the service, further fixed as well as variable costs have to be added.

The initial development efforts for the backend system depends largely on the existing system infrastructure of the participating insurance company. As existing systems within the insurance industry are heterogeneous, fragmented, and complex, it is very likely that the participating insurance company would have to invest in a new (service-oriented) system in order to allow for an exchange between the context-aware insurance system and existing systems (such as customer relationship management, workflow management, or databases) with limited subsequent maintenance requirements.

Alternatively, a solution in which the insurance company does not change its technical infrastructure to a service-oriented structure could be feasible. However, it may become difficult to ensure the exchange of information between the context-aware system and existing systems. In addition, customised development for the integration of the new system would be required, which may exceed reasonable investment and may also subsequently involve high maintenance efforts. Independent from the decision between going service-oriented or maintaining the basic infrastructure as is, skilled staff has to be available for the development of the base station and the backend system. Whether realised with in-house capacities of the insurance company or being outsourced to an information technology (IT) company, the insurance company has to bear the costs for the customised development.

Furthermore, it has to be considered that the envisaged context-aware service could imply competition with companies outside the insurance industry because, in recent years, developments in security solutions for 
works of art have emerged on the market, offering theft prevention and asset tracking solutions. However, these solutions were developed for museums and similar institutions with a security infrastructure and security personnel. Therefore, these are doing well by being based on active ultra-long-range RFID technologies, which only allow for tracking within buildings that are equipped with a complex RFID architecture. Consequently, these solutions cannot be compared directly to the proposed solution.

Finally, valuation challenges exist in estimating the system's benefits prior to its actual implementation. The challenges for determining the tangible benefits of the context-aware system ex ante relate to the inability to identify the probability for recovering stolen items, the reduction in damages due to environmental conditions as well as determining the potential increase in customer loyalty and brand awareness that is hoped for as a result from such a product offering. Measuring the value of the context-aware service after it has been implemented should be rather straightforward since the recovery rate would be known, which allows for determining the reduction in settlement payments and, to some degree, the increase of customer loyalty.

Insured Customers. From the perspective of the owners of high-value items, a basic requirement for the success of the context-aware system lies in their willingness to have their high-value items tagged which, however, may constitute a major barrier to them. From a financial perspective, though, the investment in tags and base station are quite low; still, it has to be decided whether the customer or the insurance company will pay for them (or how costs should be split).

Online Tracking Provider, Art Loss Registry, and Interpol. The online tracking provider, the Art Loss Registry, and Interpol do not have to directly contribute financially, but they need to provide their services and show some commitment to keep them alive. In case of a cooperation with police departments and/or a security company, these institutions may have to upgrade their systems and use recent RFID-, camera- and Internet-enabled mobile devices.

4.7. Feasibility Analysis. Next, the feasibility with respect to required contributions and investments for the realisation of the context-aware service will be investigated.

Insurance Company. An insurance company has to invest in reshaping its existing systems in order to achieve a smooth integration with the envisaged context-aware service. Under the assumption that it will be an insurance company that ultimately will drive the implementation of the business idea, the necessary commitment can be expected, because anticipated benefits are higher than projected costs and risks. Furthermore, insurance companies are under pressure to develop effective measures for controlling claim costs.

With respect to implementation, several challenges need to be overcome. The miniaturisation of GPS modules is technically feasible, although price may be an issue. Further, security concerns exist with respect to RFID; guaranteeing RFID security, thus, remains a challenge [19]. The availability of skilled staff for the development of the base station and the backend system can also cause problems in the realisation of the context-aware service. Then, assisted-GPS technology [24] has been introduced to enable indoor location capabilities, but these do not guarantee availability or accuracy of the coordinates. The issue could be resolved through the combined positioning capabilities of the Galileo Positioning System and more advanced cellular networks. An indoor positioning system (IPS) would be an option, but it does not comply with the international standard ISO/IEC 24730 on real-time locating systems (RTLS). Moreover, the validation of the required RFID transmission range within different building types constitutes another challenge. This will be particularly difficult in historic buildings due to the notoriously thick walls. Furthermore, burglar may scan RFID tags using an advanced custom-built RFID antenna which would pose problems with trustworthiness and system security.

Finally, estimations concerning the initial developing efforts for the backend system are tricky without knowledge on the actual system infrastructure at the insurance company. Accordingly, evaluations can only be based on experience and rough estimates. Costs therefore have to be assessed on a case-by-case basis with a thorough understanding of the underlying IT architecture.

Insured Customers. The owner of a high-value item is likely to adopt this novel form of monitoring because of the significant financial value and the high emotional value of the items. However, there could be a psychological barrier for them to apply a tag to such a highly valued item. Basically, there are two options 
for installing a tag, either as part of the highly valued item or attached to its container. If installed as part of an item (for instance, drilling a small hole in a statue, placing the tag, and restoring the hole professionally; or sticking a tag non-detachably to the back of a painting), a potential thief could not remove the tag from the item without damaging the item. However, even when the installed tag is invisible, it alters the item, which may cause a devaluation in case of resale. If the tag is attached to an item's container, the item remains in its original condition, but a potential thief may easily withdraw the item from its container, making the precautious tag instalment ineffective. In essence, there is a trade off between 'effective instalment, but compromising the item' versus 'preserving the item, but the instalment may potentially be easily circumvented by a thief'. Compared to the improved likelihood to recover stolen items and to avoid damages by the environment, this barrier should, however, be easy to overcome.

Online Tracking Provider, Art Loss Registry, and Interpol. We assume that the online tracking provider, the Art Loss Registry, and Interpol would participate in this context-aware service, since they do not require any investment, because they have their services ready to provide.

4.8. Cost-benefit Analysis. Costs (as well as their trends) for necessary technical components may be derived from data being available for similar components used in existing asset tracking systems. Cost estimates for the software components used in the base station turn out to be more difficult. Two assumptions regarding their costs have to be made: We assume that the software must be custom-built which requires highly skilled programmers and that GPRS and RFID or sensor filtering software will be available as software components and, thus, require only simple configuration and/or low modification efforts.

Further estimates are required to determine the potential economic valuation of the proposed solution, assuming that a single insurance company will invest into the development and installation of the system. Assuming an equal market share distribution for the top three insurance companies in a country, an approximate claim settlement payments per year can be calculated. Considering an estimated growth rate of, for instance, ten percent for theft incidents and a time frame of five years, the break-even can be estimated. Table 4.6 lists the identified cost drivers including the estimates that are necessary for an evaluation.

TABLE 4.6

Overview on cost drivers and estimates

\begin{tabular}{lr}
\hline Cost Drivers & Estimates \\
\hline Semi-passive RFID Tags inclusive Sensors & Number of Customers \\
Base Station (RFID Reader, GPRS Module & Average Number of Tagged Items per \\
and Software Component) & Customer \\
Backend Application Server & Hourly Cost of Installation \\
Database and Storage Server & Development Cost per Person-day \\
Software Development (Base Station) & Discount Rate \\
Software Development (Monitoring) & Theft Growth Rate \\
Software Development (Frontend) & \\
Personnel (Installation) & \\
\hline
\end{tabular}

Strauss et al. [27] recommend scenarios for such an economic evaluation. Following this approach, we developed the four scenarios depicted in Tab. 4.7 for which we distinguish between pessimistic and optimistic parameters concerning the value of the novel service (e.g., costs and tangible benefits) as well as between aggressive and more conservative assumptions with respect to the customer base or the number of insured high-value tagged items.

All costs for hardware development and installation have to be included in the evaluation. A difference of roughly fifty percent between pessimistic and optimistic values can be chosen to account for extreme conditions. Software development efforts are estimated assuming that the software is customised, the development can be split for the base station, monitoring, and portal software components, and the fees do not exceed standard lowcost programming fees charged by Eastern European system integrators. Integration efforts have to be excluded at this point, due to the lack of information with respect to existing systems. Assuming a standards-based service-oriented architecture IT infrastructure, the development of the necessary interface and service elements could be considered part of the estimated development efforts. Additional backend hardware components 
TABLE 4.7

Systematic scenario development

\begin{tabular}{|c|c|c|c|}
\hline & & \multicolumn{2}{|c|}{ Value } \\
\hline & & Pessimistic & Optimistic \\
\hline \multirow{2}{*}{ 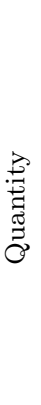 } & 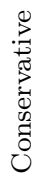 & $\begin{array}{l}\text { Scenario I } \\
\text { Costs - high } \\
\text { Tangible Benefits - low } \\
\text { Customer Base - small } \\
\text { Number of Items - few }\end{array}$ & $\begin{array}{l}\text { Scenario II } \\
\text { Costs - low } \\
\text { Tangible Benefits - high } \\
\text { Customer Base - small } \\
\text { Number of Items - few }\end{array}$ \\
\hline & $\begin{array}{l}0 \\
. \\
0 \\
0 \\
0 \\
0 \\
\infty \\
\infty \\
4\end{array}$ & $\begin{array}{l}\text { Scenario III } \\
\text { Costs - high } \\
\text { Tangible Benefits - low } \\
\text { Customer Base - large } \\
\text { Number of Items - many }\end{array}$ & $\begin{array}{l}\text { Scenario IV } \\
\text { Costs - low } \\
\text { Tangible Benefits - high } \\
\text { Customer Base - large } \\
\text { Number of Items - many }\end{array}$ \\
\hline
\end{tabular}

are required, which may include up to two application servers and four database (i.e., storage) servers for the monitoring and portal components. Server hardware costs may be based on current market values given relatively stable price dynamics.

For the context-aware insurance service, a professional appraiser would determine the value of each highvalue item. Including initial training, the appraiser could tag the items and install the base station. The installation cost per customer depends on the number of items per customer, the hourly wage of specialists for the appraiser (based on the level of the country where the items are located, as installations have to be made on site), and an estimated time frame between five and twelve hours for installation of the system at the customers site. Furthermore, the recovery rates of stolen items have to be estimated.

Additional variable costs may include maintenance for further software development, system support, employee training, and mobile data communication charges. Mobile data communication charges depend on the amount of information being transmitted. The base station would require more information being sent at less frequent intervals while the GPS tracking module would send less information more frequently. Based on calculations from existing systems a GPS tracking node transmitting its location every ten seconds, 24 hours a day, seven days a week would amount to a total data volume of less than ten megabytes per month per item [12].

Combining the above estimates in the four different scenarios with the internal variables of an insurance company allows for the quantitative evaluation of a specific real-world business case.

5. Conclusions. So far, the potential of context-aware computing has been recognised only in a few industries such as manufacturing or retail in which some context-aware applications have been introduced. In several other industries, however, context-aware computing has experienced just very limited exposure yet. This paper discusses how the innovation potential of context-aware computing can be introduced to these industries by following a rather business-oriented instead of a technology-driven approach. To this end, we introduce a novel procedural framework that is key player-centred and allows for identifying the value of context-aware services. Based on a case study from the insurance industry, we have demonstrated the applicability of the framework with respect to a context-aware service for wireless monitoring high-value items, such as paintings, sculptures, or antiques. This service includes the surveillance of high-vale items, including tracking their location and environment conditions. As required in a multi-sided market, the realisation of this context-aware service is beneficial for each involved key player, i.e., the benefits are shown not only for the owners of high-value items, but also for insurance companies and further stakeholders.

This work thus contributes to the fields of context-aware computing and services innovation on emerging computing and communication systems in three ways: Firstly, the paper proposes a key player-centred framework that is predominantly business-value-driven and, thus, is more suitable for industries such as the insurance industry. Secondly, we discuss a context-aware service that involves several key players, and that provides a 
viable solution to the immediate threats confronting insurance companies. Their customers would benefit from an increased protection of their high-value items. Furthermore, a potential reduction in premium prices could be realised due to a network effect of overall reduced risk. From the viewpoint of the customer, the relationship between insurer and customer may shift from traditional paymaster to a problem-solving, trust-worthy helper. Both, insurer and customer, would benefit from an improved quality of service. Thirdly, from a methodological point of view, the solution has potential of being readily adopted by market players. Experience has shown that the full potential of a context-aware computing solution can be effectively determined through the development of a pilot project. Pilot projects support the understanding how context-aware computing solutions may effect revenue and cost of business, and allow for detailed, quantitative business case evaluation. Furthermore, pilot projects may assist in determining how potential users perceive the benefits of the system, and whether or not they have reservations due to possible privacy implications or psychological constraints (e.g., for having high-value items tagged).

Future work will focus on the development of a real-world business case. Researchers are encouraged to apply the suggested framework in various industries to identify new, valuable business cases. Concluding, it will be interesting to see to what extent companies will ultimately embrace the technology and use it as a means for their differentiation from competitors on the market.

\section{REFERENCES}

[1] Art Loss Registry, Website of art loss registry, http://www.artloss.com/. Accessed 12 August 2013.

[2] L. Auer, E. Belov, N. Kryvinska, and C. Strauss, Exploratory case study research on SOA investment decision processes in Austria, in Advanced Information Systems Engineering, Lecture Notes in Computer Science, H. Mouratidis and C. Rolland, eds., Volume 6741, 2001, pp. 329-336.

[3] C. Bauer, P. Dohmen, And C. Strauss, Interactive digital signage: an innovative service and its future strategies, International Conference on Emerging Intelligent Data and Web Technologies (EIDWT 2011) \& International Workshop on Frontiers in Service Transformations and Innovations (FSTI 2011), 7-9 September 2011, Tirana, Albania, 2011, pp. 137142 .

[4] C. Bauer and S. Spiekermann, Conceptualizing context for pervasive advertising, in Pervasive Advertising, J. Mueller, F. Alt, and D. Michelis, eds., Springer, London, United Kingdom, 2011, pp. 159-183.

[5] V.-T. Do, M. Halatchev, And D. Neumann, A context based approach to support virtual enterprises, Hawaii International Conference on System Sciences (HICSS '00), 4-7 January 2000, Maui, HI, 2000, pp. 1-10.

[6] A. S. Dobson, Leveraging the subtleties of location, Smart Objects and Ambient Intelligence (sOc-EUSAI 2005), 12-14 October 2005, Grenoble, France, 2005, pp. 189-193.

[7] D. W. Engels And S. E. SARMA, Standardization requirements within the RFID class structure framework, MIT Auto-ID Labs Technical Report, 2005.

[8] E. FleISCH AND C. TELLKAMP, The challenge of identifying value-creating ubiquitous computing applications, International Conference on Ubiquitous Computing (UbiComp 2003), Workshop on Ubiquitous Commerce, 12-15 October 2003, Seattle, WA, 2003

[9] M. Friedewald AND O. RAABE, Ubiquitous computing: an overview of technology impacts, Telematics and Informatics, 28, 2 (2011), pp. 55-65.

[10] B. Friedman, Value-sensitive design, Interactions 3, 6 (1996), pp. 16-23.

[11] P. I. Furseth, R. Cuthbertson, And J. Reynolds, The value dynamics of service innovation, ISPIM Conference, 69 June 2010, Bilbao, Spain, 2010.

[12] GPSauge, Website of GPSauge, http://www.gpsauge.de/. Accessed 12 August 2013.

[13] M. HAAs, The formation process of SME networks: a comparative case analysis of social processes in Austria, Belgium and Turkey, Deutscher Universitätsverlag, Wiesbaden, Germany, 2007.

[14] A. R. Hevner, S. T. March, J. PARK, And S. Ram, Design science in information systems research, MIS Quarterly, 28, 1 (March 2004), pp. 75-105.

[15] InTERPOL, Works of art: recent thefts, http://www.interpol.int/Crime-areas/Works-of-art/Recent-thefts. Accessed 12 August 2013.

[16] D. A. KAnKAInEn, UCPCD: user-centered product concept design, Conference on Designing for User Experiences (DUX 2003), 5-7 June 2003, San Francisco, CA, 2003, pp. 1-13.

[17] G. Kortuem, F. Kawsar, D. Fitton, and V. Sundramoorthy, Smart objects as building blocks for the Internet of Things, IEEE Internet Computing, 14, 1 (January/February 2010), pp. 30-37.

[18] R. Kumar, Y. Lifshits, and A. Tomkins, Evolution of two-sided markets, ACM International Conference on Web Search and DataMiniing (WSDM'10), 4-6 February 2010, New York, NY, 2010, pp. 311-319.

[19] A. Newitz, The RFID hacking underground, iWired News, Wired 14.5 (May 2006), 2006, http://www.wired.com/wired/archive/14.05/rfid.html. Accessed 12 August 2013.

[20] D. A. Norman AND S. W. DRAPER, User-centered system design: new perspectives on human-computer interaction, Lawrence Earlbaum Associates, Hillsdale, NJ, 1986. 
[21] A. OulasvirTa, Finding meaningful uses for context-aware technologies: the humanistic research strategy, SIGCHI Conference on Human Factors in Computing Systems (CHI 2004), 24-29 April 2004, Vienna, Austria, 2004, pp. 247-254.

[22] Z. PAng, Q. Chen, W. Han, and L. Zheng, Value-centric design of the internet-of-things solution for food supply chain: value creation, sensor portfolio and information fusion, Information Systems Frontiers, August 2012, pp. 1-31.

[23] J. Pries-Heje, R. Baskerville, and J. Venable, Strategies for design science research evaluation, European Conference on Information Systems (ECIS 2008), 9-11 June 2008, Galway, Ireland, 2008, pp 255-266.

[24] B. Richton, G. Vanucci, and S. Wilkus, Assisted GPS for wireless phone location-technology and standards, S. Tekinay, ed., Next generation wireless networks, Norwell, MA, Kluwer Academic Publishers, 2001, pp. 129-155.

[25] D. Schuler, Social computing, Communications of the ACM, 37, 1 (1994), pp. 28-29.

[26] S. Shane, Reflections on the 2010 AMR decade award: delivering on the promise of entrepreneurship as a field of research, Academy of Management Review, 37, 1 (2012), pp. 10-20.

[27] C. Strauss, C. Stummer, C. Bauer, And A. Trieb, A networked ubiquitous computing environment for damage prevention: a decision support framework for the insurance sector, International Conference on Parallel Processing (ICPP 2009) \& International Workshop on Design, Optimization and Management of Heterogeneous Networked Systems (DOMHetNetS'09), 22-25 September 2009, Vienna, Austria, 2009, pp. 276-281.

[28] B. W. Tuckman and M. A. C. Jensen, Stages of small-group development revisited, Group and Organization Studies, 2,4 (December 1977), pp. 419-427.

[29] J. Venable, J. Pries-Heje, and R. Baskerville, A comprehensive framework for evaluation in design science research, International Conference on Design Science Research in Information Systems and Technology (DESRIST 2012), 1415 May 2012, Las Vegas, NV, 2012, pp. 423-438.

Edited by: Ethiopia Nigussie, Andreas Riener and Liang Guang

Received: Sep 1, 2013

Accepted: Sep 28, 2013 